\title{
Design of evacuation plans for densely urbanised city centres
}

João Coutinho-Rodrigues CEng, MSc, PhD, Aggr

Researcher, Institute for Systems Engineering and Computers (INESC), Coimbra, Portugal; Full Professor, Department of Civil Engineering, University of Coimbra, Coimbra, Portugal

Nuno Sousa MSc, PhD

Researcher, Institute for Systems Engineering and Computers (INESC), Coimbra, Portugal; Assistant Professor (invited), Department of Sciences and Technologies, Open University, Lisbon, Portugal
Eduardo Natividade-Jesus CEng, MSc, PhD

Researcher, Institute for Systems Engineering and Computers (INESC), Coimbra, Portugal; Assistant Professor, Department of Civil Engineering, Polytechnic Institute of Coimbra, Coimbra, Portugal

The high population density and tightly packed nature of some city centres make emergency planning for these urban spaces especially important, given the potential for human loss in case of disaster. Historic and recent events have made emergency service planners particularly conscious of the need for preparing evacuation plans in advance. This paper discusses a methodological approach for assisting decision-makers in designing urban evacuation plans. The approach aims at quickly and safely moving the population away from the danger zone into shelters. The plans include determining the number and location of rescue facilities, as well as the paths that people should take from their building to their assigned shelter in case of an occurrence requiring evacuation. The approach is thus of the location-allocation-routing type, through the existing streets network, and takes into account the trade-offs among different aspects of evacuation actions that inevitably come up during the planning stage. All the steps of the procedure are discussed and systematised, along with computational and practical implementation issues, in the context of a case study - the design of evacuation plans for the historical centre of an old European city.

\section{Introduction}

Earthquakes, fires, floods, hurricanes, acts of terrorism, accidents with hazardous materials, nuclear accidents and other catastrophes that may occur in or affect urban areas are an important concern for emergency services and a timely issue in urban engineering planning.

Decision-makers are becoming increasingly aware of the importance of preparing for emergency situations, as recent research in municipal engineering attests. Issues focused by this research cover a wide range of subjects such as - for example, the importance of georeferenced data for enabling emergency services (Yildirim et al., 2014); the effect of official directives such as the UK Civil Contingencies Act 2004 (2004), in planning for, and response to, civil emergencies (Stainsby, 2012); the importance of risk planning for critical urban infrastructures (Booth, 2012); resilience of these infrastructures to cope with system shocks, whether from natural hazards, terrorism or catastrophic failures (Rogers et al., 2012); and awareness of the growth of flooding events risk, which are very costly for insurers (McRobert, 2010). With respect to this later issue, according to the Institution of Civil Engineers, flooding and its effects on infrastructure has been a recent key concern in the UK, and with climate change and sea level rise, incidences of flooding are expected to become more frequent (Miller, 2014).

The human and financial losses related to emergency events varies but can reach very large figures (for example, see http:// www.statista.com/statistics/267210/natural-disaster-damage-totalsworldwide-since-1970/ (accessed 18/05/2015)), with insurance losses in the order of billions of US\$. Urban emergency events may cause the necessity to evacuate affected areas, even for smaller situations. As Murray-Tuite and Wolshon (2013) recognise, evacuations are in reality more frequent than commonly thought - these authors claim that an evacuation of 1000 or more people occurs about once in every 2-3 weeks in the USA.

Recent examples of large-scale evacuation orders are Hurricane Sandy (October 2012), which gave rise to mandatory evacuation for 'zone A' residents of New York City (McAlinden, 2014), and Hurricane Katrina (August 2005), whose effects on New Orleans are also well known - a mandatory evacuation of the city was ordered, but many people refused to leave; pre- and post-hurricane evacuations displaced more than 1 million 
people (ASCE, 2007a). At their peak, hurricane evacuee shelters housed 273000 people (Plyer, 2015). Terrorist attacks have also caused renewed interest in developing effective policies and strategies for evacuating densely populated structures or facilities (Gershon et al., 2012; Kicinger and Bronzini, 2006). The above makes it clear that the relevance of evacuation planning is likely to increase in the coming years (see also ASCE, 2007b; Kunwar et al., 2014).

Evacuation is a process in which threatened people are displaced from dangerous places to safer places, as a response to an approaching hazardous event or in the aftermath of it; from the point of view of urban engineering, this topic can be approached in several ways, as described below.

Usually, evacuation time is one of the main objectives considered in the design of evacuation plans - it is especially important for unpredictable disasters - for example, man-made disasters such as terrorist attacks or accidents occurring during the transportation of hazardous materials (Erkut and Ingolfsson, 2000; Kara and Verter, 2004; Verma et al., 2011). In these situations, evacuation is urgently required after occurrence, and must therefore be conducted in a short time, making total evacuation time period a critical objective (Liu et al., 2007). Traffic flow is another important evacuation aspect per se, as the recent review on highway-based evacuation by Murray-Tuite and Wolshon (2013) shows (see also Brachman and Dragicevic, 2014), frequently done in tandem with time aspects (Kunwar et al., 2014; Lim et al., 2012; Mishima et al., 2014; Sayyady and Eksioglu, 2010; Stella and Daganzo, 2010). Scheduling aspects of evacuation problems are also approached, as in the evacuation scheme based on the use of buses presented by Goerigk et al. (2013). For predictable disasters, which mainly are natural disasters such as hurricanes or floods, evacuation is required before disaster happens and the main objectives under this situation may be to minimise the system costs of evacuation and path risk, and to find the best location for rescue facilities (Kailiponi, 2010; Kongsomsaksakul et al., 2005; Li et al., 2012; Sherali et al., 1991). Locational aspects actually have a long tradition in emergency planning (Chang et al., 2012; Chu and Su, 2012; Daskin, 1982; Daskin and Stern, 1981; ReVelle, 1989; ReVelle and Snyder, 1995; Saadatseresht et al., 2009; Schilling et al., 1979, 1980; Toregas et al., 1971).

Selecting an approach will depend on the nature of the event that triggered the evacuation call and on the characteristics of the area to be evacuated. In the case of densely urbanised city centres, particularly old European city centres, motorised evacuation is often difficult or outright impossible (D'Orazio et al., 2014), forcing decision-makers to consider walking as the transport mode. Due to the limited length that a person can walk, and due to safety reasons, it is natural to consider moving the affected population to nearby shelters, where they can gather up safely, thus putting the focus on locational and routing issues. These shelters should be endowed with adequate infrastructure to receive population (e.g. tents, first-aid medical assistance).

Regardless of the approach followed, it is clear that urban evacuation is a complex problem with multiple, possibly conflicting, objectives, such as - for example, path length, path risk, shelter risk and accessibility, operational costs and so on, often needing to be addressed simultaneously. This manifold nature of urban evacuation adds to the complexity of the problem and justifies the development of methodologies, based on multiobjective decision-making approaches, to solve the problem. However, the use of a multiobjective approach as the main core of the methodological approach is complicated by three difficulties. First, these problems, which include locational aspects, are difficult to solve even for single-objective problems, mainly because if real sizes are considered mathematical models may become very complex. Second, as generally there is no single solution for all the objectives, the concept of optimum solution is replaced with that of a non-dominated (efficient, non-inferior or Pareto-optimal) solution (Cohon, 1978); this leads however to a significant rise in the number of solutions to be generated. Third, as the number of objectives increases, the analysis of the trade-offs among these objectives and among the various non-dominated solutions becomes more difficult. Therefore, adequate techniques to generate and compare solutions must be adopted.

This paper proposes a strategy or methodology to plan for an evacuation action on a densely urbanised city centre, based on multiobjective optimisation and organised in a sequence of well-defined steps. Special importance was assigned to problem structuring aspects, as this is a widely acknowledged issue in decision-making methodologies (Belton and Stewart, 2010). The core idea of the strategy, which focuses on locationallocation-routing aspects of evacuation, is to indicate which path should an evacuee follow to reach a (model-chosen) shelter, and to give her/him an alternative path to a backup shelter, should the first path be blocked due to the triggering event. It must be stressed that the methodology assumes that paths leading to shelters are restricted to traffic, or otherwise not practical for automobile use. Motorised access is only assumed to be possible from shelters to the nearest hospital (and this fact is taken into consideration in one of the steps). The typical urban landscape for the strategy consists of zones with many narrow/restricted streets and/or zones that may allow for some traffic but for which evacuation by foot may be faster or more convenient than by motorised means (e.g. if it is always feasible to place a shelter within $500 \mathrm{~m}$ distance from any evacuees - a reasonable, if not conservative, walking distance (Marquet and Miralles-Guasch, 2014)). In the case study section, two images are given that exemplify the type of 
urban morphology for which the methodology proposed is best suited for. Note also that the methodology treats evacuation actions at a wide reaching, broad level, which may serve as a basis to be conveniently adapted for particular situations. The aspects it deals with, albeit generic, are nevertheless consensual in the literature and cater for the most of issues that arise in practice. Provision of a backup path, for instance, can help resolving cases where the triggering event takes place within the area to be evacuated and blocks some of the streets.

Achieving the goal of designing evacuation plans for the above-mentioned contexts requires the application of several techniques in succession, which are described below, in Section 2. The outcome of it is one turnkey methodology to plan for an evacuation that can be widely applied by municipal authorities. Section 3 contains a case study application to the old city centre of Coimbra, Portugal, together with some conclusions. A summary and outlook are presented in Section 4.

\section{Evacuation strategy for densely urbanised city centres}

The evacuation strategy proposed here applies to situations of densely urbanised zones, with an urban morphology (common in old European cities) that consists mainly of narrow streets and small buildings, for which pedestrian evacuation is preferable. It takes into consideration a series of sought-after objectives in evacuation planning, which have not been treated simultaneously in the literature, making the approach very complete. It is also self-contained and widely applicable to real cases. The methodology involves four steps: (1) A preparatory step, where data concerning geographic and demographic aspects, buildings and streets characteristics are gathered and treated, with an aim to clearly define the problem mathematically and setting its bounds. (2) A routing step, based on biobjective shortest path generation, where paths from demand clusters (building sectors) to supply centres (shelters) are calculated, minimising path length and path risk. (3) A location-allocation step, where the previously derived paths are judiciously selected, in a multiobjective set-up, to allocate the population in sectors to shelters. (4) A round-up step, where the multiple solutions are examined by the decision-maker and one is selected for implementation on the field. Geographical information systems (GIS) are an ideal tool for assisting in all these steps, particularly (1) and (4). The four steps are described in detail below.

\subsection{Step 1: data survey and clustering}

Defining the evacuation problem requires gathering and handling extensive data concerning the study area. The decision maker needs to follow the following steps.

- Delimit the area to be evacuated: This task depends on guidelines from the municipal authorities; the delimiting usually encapsulating packed city centres consisting of residential areas, services and commercial areas, sided by narrow streets that preclude motorised evacuations.

- Collect and register data: The following are needed: streets network of the evacuation area, population present in buildings and building characteristics, such as - for example, data for evaluating their respective conservation status (as defined by e.g. AQ, 2011; DCLG, 2006; Natividade-Jesus et al., 2013; NEN, 2006). The latter information is necessary to define path and shelter risk. Data collection may require standard techniques also used in other problems of surveying, infrastructure management and urban engineering (census and cadastral data may be used, complemented by in situ additional survey).

- Identify and characterise candidate shelter locations: These are normally squares or parks, and can sit inside the evacuation area or at the edge of it. They should be easily accessible by the evacuees and have connections to main streets which healthcare vehicles can use. Capacity constraints need to be defined at this stage, as well as shelter risk and transport time to the nearest hospital (these will be used later in the models). Civil defence authorities can help setting the maximum population, whereas economic factors may dictate minimum serviced population that justifies the statute of candidate shelter. Like path risk, the definition of shelter risk is arbitrary, but a priori it should depend on the conservation status (which must be assessed) and other characteristics of surrounding buildings, such as - for example, fire risk (Dobbernack and Klingenberg, 2005; Larsson, 2000; NFPA, 1995, 2001). Transport time to the nearest hospital can be evaluated in GIS using standard network analysis tools. Shelter should be set up considering the nature of the hazard the decision maker wishes to protect against, while preferably keeping some flexibility for other types of disaster.

- Define building sectors: This is done to reduce complexity and can be achieved by clustering groups of buildings along street segments of $50-100 \mathrm{~m}$. Each cluster is a 'sector' and all the buildings in the sector get assigned to the same shelter. The task is usually carried out in the GIS.

- Assign risk to network arcs: As for shelters, the decision-maker defines what arc risk is. Factors that can be considered are - for example, street factors (width, length, pavement type and conservation, obstacles), surroundings factors (conservation status and fire risk of adjacent buildings) and arc length. The outcome is stored in GIS as a field associated to the network arcs.

As a concluding remark, the decision-maker may wish to consider day and night instances separately, as there is usually less people to evacuate at night but higher risks. For example, in what concerns residential fires, half of all home fire deaths 
result from incidents reported between 11:00 p.m. and 7:00 a.m. (Ahrens, 2015).

\subsection{Step 2: calculate individual evacuation plans}

Having defined sectors, identified candidate shelters and characterised the streets network, it is now possible to identify the best paths for going from sectors to shelters. For this purpose, for each sector-shelter combination, a biobjective routing algorithm is executed using operational research techniques described in the literature (e.g. Coutinho-Rodrigues et al., 1999), aiming at minimising both path length and path risk in going from sector to shelter (path risk is the sum of the path's arcs risks). The algorithm can be implemented in several ways, but the simplest is to run it on a weighted sum (Cohon, 1978) approach, for different weights of path length and path risk (e.g. 100/0, 50/50, 0/100 etc.). Of the paths found this way, some will actually be the same (this happens more often for lower sector-shelter distances). Duplicates are removed, as well as paths with length or risk higher than an equity cut-off defined by the decision-maker (ReVelle and Eiselt, 2005). These paths are called 'primary paths', and the shelter each leads to is the 'primary shelter'.

Figure 1 shows the concept of primary path calculation, along with an in situ demonstration, taken from the case study.

Since primary paths may be blocked by the triggering event itself, a backup plan should therefore be prepared. Figure 2 shows the concept.

Existence of secondary, backup paths is recommended by evacuation planning authorities such as the US Fire Administration. To achieve this, the routing algorithm is rerun as follows: for each sector, consider primary paths stemming from it and, for each shelter-primary path instance,
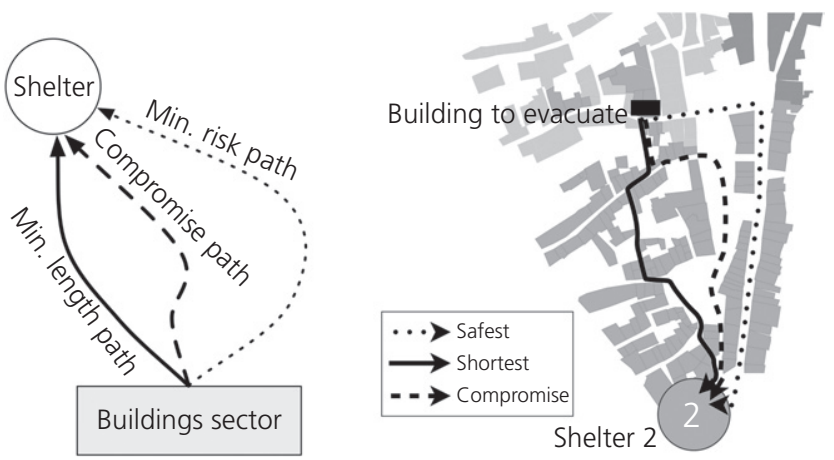

Figure 1. Generation of primary paths

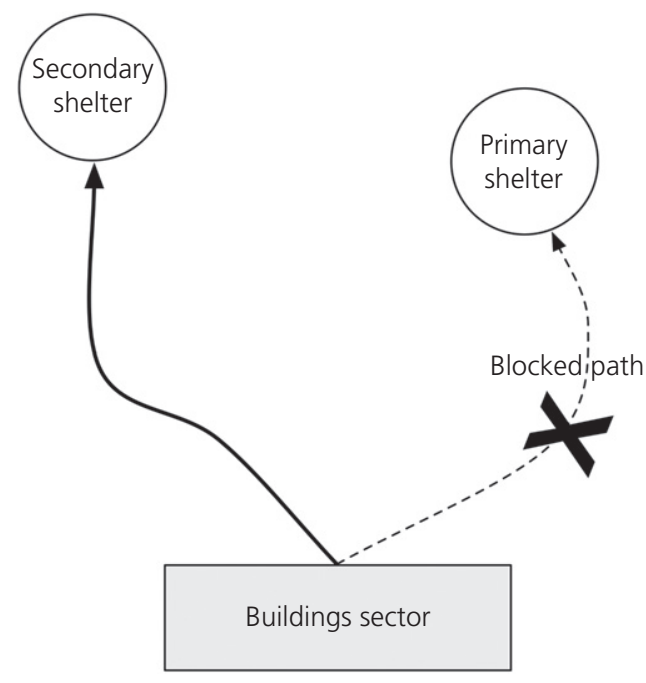

Figure 2. Secondary path and shelter (concept)

add artificial very high length costs to arcs of that primary path and nearby arcs, so as to penalise them (this models a blocked path for network analysis purposes). Then, for each instance, derive shortest length paths from the sector to all shelters (risk not considered). The shortest of these sectors-to-all shelters paths tree becomes the 'secondary path' of the respective sectorprimary path instance, and its endpoint the 'secondary shelter' (this is described in more detail in Coutinho-Rodrigues et al., 2012 - see Appendix 1). The procedure usually yields a secondary shelter different from the primary one.

A sector, a primary path, a secondary path and an identifier constitute a tuple designated by 'individual plan'. The outcome of step 2 is thus the formation of a large pool of individual plans.

\subsection{Step 3: optimise allocation to shelters (global evacuation plans generation)}

Step 3 consists of finding optimised ways to assign, to each sector, one, and only one, individual plan. Selecting the individual plans is done according to the model of CoutinhoRodrigues et al. (2012), which seeks to minimise six objectives relevant for evacuation purposes, namely: primary path length $(\mathrm{O} 1)$; primary path risk $(\mathrm{O} 2)$; secondary path length $(\mathrm{O} 3)$; primary shelter risk $(\mathrm{O} 4)$; transportation time to the nearest hospital (O5); number of open shelters (O6), subject to capacity constraints on the population allocated to open shelters. Objectives $\mathrm{O} 1-\mathrm{O} 4$ and $\mathrm{O} 6$ refer to what civil defence authorities call 'primary evacuation actions' (moving people to safe locations), whereas O5 refers to 'secondary evacuation actions' - that is, follow-up actions after people are gathered in those locations. To the best of the authors' knowledge, this is 
the only evacuation model that addresses these two types of actions simultaneously.

The model's mathematical formulation can be consulted in Coutinho-Rodrigues et al. (2012). All the population from sectors whose primary path ends on a given shelter gets allocated to that shelter. An 'open (closed) shelter' is a shelter that has (has not) population allocated to it.

Allowing only open shelters as possible secondary shelters can be too restrictive. Due to this, the model is run considering any candidate shelter as a viable secondary shelter. Consequently, the population of sectors that get assigned (by the individual plan) to a closed secondary shelter should be redirected to an open one, preferably by way of a path at the edge of the disaster zone (Figure 3). If redirecting is (is not) considered, the model is deemed 'extended (simple)'. Redirecting adds extra length to the secondary path, weighted by a factor that should not exceed 0.5 because the extra length is at the edge (thus it is safer).

Model calculations can be performed with a mixed-integer linear programming (MILP) solver or using heuristic methods, with evolutionary algorithms particularly fit for the latter case. MILP calculations yield exact solutions, but are restricted to relatively small problem instances and have more limitations when it comes to generating solutions. The weighted sum method is proposed for this purpose, which boils down to assigning a weight to each objective and summing up all objectives. Furthermore, calculations in the extended version of the model give rise to a considerable increase in the number of binary variables, making the MILP approach unusable for all but very small instances. Nevertheless, heuristic approaches,

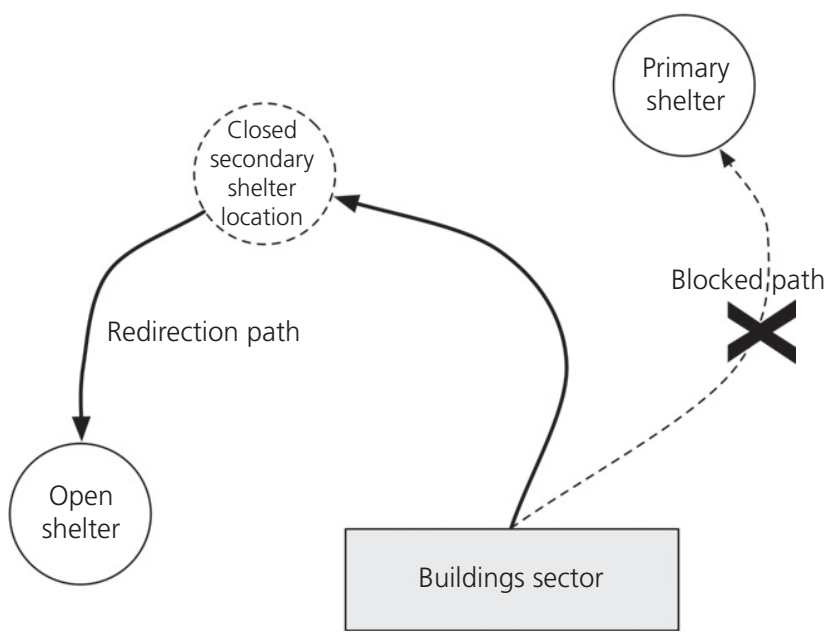

Figure 3. Redirecting for secondary paths (concept) yielding approximate results but running faster, can be applied to any problem size and model variation (simple or extended). More importantly, they can yield the Pareto front of the problem, rather than having to resort to weighted sum methods to obtain only a few non-dominated solutions. Having the Pareto front (or a meaningful set of representative solutions thereof) is important for the decision-maker, as it enables him to have a broader look at the trade-offs that can be made among the various objectives.

Two technical issues regarding model-related calculations need attention. The first issue is that individual optima should be found before assigning arbitrary weights. These are necessary to normalise objectives, so that these stand the same ground previously to weights assignment. Normalisation can be done in various ways (e.g. Tralhão et al., 2010). The second is the lack of 'all sectors-to-all shelters' feasible paths, which are in general 'not' available due to the maximum length/risk equity cut-offs.

Due to the second issue, if genetic algorithms (GA) are used and shelter information is included in the chromosome architecture, perturbations arise when open/closed status of shelters is toggled during evolution. Indeed, reassignment of people to new shelters may cause loss of good genetic information and the convergence process is slowed down. Further slowdowns are caused by routines that must be constantly run to avoid spawning of invalid offspring. A way around this second problem is to use a 'divide-and-conquer' strategy, consisting on predetermining the open shelters and running a loop through all the feasible shelter combinations. Each of these combinations is a sub-problem of its own, of a smaller dimension because invalid individual plans can be removed (plans that would lead to closed primary shelters). The chromosome of each sub-problem can be represented simply by

$$
\left(x_{1}, x_{2}, x_{3}, \ldots, x_{N_{\mathrm{s}}}\right)
$$

where $N_{\mathrm{s}}$ is the number of sectors with $x_{k}$ being an identifier indicating which individual plan is selected for sector $k$, out of the valid ones for the sub-problem at hand. The divideand-conquer strategy also guarantees better results for front searching methods, which are typically more difficult to solve than weighted sum approaches. Fronts obtained for the subproblems (local fronts) need, however, to be gathered up and compared, so as to remove dominated solutions from the final (global) front. The downside of divide and conquer is that the central processing unit (CPU) time can be spent in shelter combinations that ultimately turn out to be uninteresting. However, under that strategy it is possible to synergise weighted sum and front searching approaches by running them in this sequence: (a) obtain O1-O6 optima from weighted 
sum; (b) normalise objectives and run front searching methods for high CPU time; (c) assign typical weights to front solutions and identify the best solution for each weights combination, taking note of the corresponding shelter combination; and (d) continue searching only on the shelter combinations that appear more often in step $(c)$.

Due to the combinatorics involved, divide and conquer can only be applied for a small number of candidate shelters. For more shelters, a zoning scheme - that is defining zones and selecting one to two shelters per zone, can keep the number of shelter combinations low. When zoning, population density and shelter proximity should be taken into account. Even larger problems require, however, including shelter selection information in the chromosome and having to deal with the algorithmic problems mentioned above.

\subsection{Step 4: analyse output, select and operationalise a solution}

Regardless of the way solutions to the allocation problem are obtained, the decision-maker should always analyse at least a few of them, so as to gain intuition as how the trade-offs among objectives work for each particular evacuation problem. Thus, results should be derived for weights combinations reflecting the choices of the decision maker with emphasis on - for example, shorter paths, lower risk, less shelters and so on. The choice of a particular solution for implementation will nevertheless ultimately remain a political choice, as is nearly always the case with multiobjective problems. For a comparison of solutions, adequate graphical display techniques such as Best AGainst Least (BAGAL) (Alçada-Almeida et al., 2009) may be adopted.

Operationalisation of a solution consists of civil defence measures and passing information to the people inside the buildings. Civil defence authorities would take responsibility to prepare primary shelter locations for receiving the evacuees and transferring the seriously wounded to the nearby hospital. Information should in turn be posted at building exits indicating where people should be heading to, and through which path, with a note indicating a backup path, to be used in case they find the first one blocked. These paths may be graphically depicted at the buildings' exits, and direction signs can also be put on street walls.

Subsequent actions include updating data from time to time and re-running the models for new solutions, or improved solutions in case heuristics are used. Training of civil defence personnel is advisable, as well as running simulation exercises.

Figure 4 contains a round-up of all the steps described above. Finally, for very large evacuation areas, where it may only be necessary to evacuate a subset thereof, authorities can divide the large area into smaller ones and apply this methodology to each division. Evacuation calls could then be issued for all endangered divisions.

\section{A case study}

The methodology presented was applied to a case study, the design of evacuation plans for the city centre of Coimbra, Portugal. The city of Coimbra dates back to the Romans and the particular test area, located in the medieval city centre, is a densely urbanised section of the city with many narrow streets and old buildings, some of them dating back to medieval times. Most of the study area is barred to motorised traffic. In Figure 5, two photographs of streets belonging to the case study zone are shown, which are representative of the whole area.

\subsection{Case study - step 1}

For the case study, an area of about 15 ha was selected and data concerning building population and streets network were available in GIS format from previous projects.

Nine candidate shelter locations were identified (squares and parking lots), with connections to main streets. Some of these were small and next to each other, so as to test sensitivity to redundancies. Minimum and maximum capacities were defined taking into account shelter size. Risk calculations used the 'fire risk index method', which took into account the characteristics of buildings adjacent to shelter edges and paths (also available from previous projects). Arc and shelter risks were then defined summing the risk indexes of adjacent buildings weighted by their construction area and number of floors. Transport times to the nearby hospital were estimated with standard GIS tools. Figure 6 shows a GIS representation of the buildings (polygons), two examples of clustering into sectors and shelter candidate site identification for the case study.

A total of 199 sectors were formed and day and night problem instances were considered, which led to 192 (143) sectors to be evacuated for the day (night) case. During the night, some sectors (mostly commercial and services buildings) become deserted and during the day others (residences) are also deserted due to inhabitants moving out to work. Table 1 summarises the data.

\subsection{Case study - step 2}

GIS data for path length and path risk were uploaded to the sector-shelter routing algorithms to generate individual plans with 11 weights combinations for path length/risk (100/0, $90 / 10, \ldots, 0 / 100)$. The length/risk equity cut-offs were of $500 \mathrm{~m}$ maximum primary path length and 500 risk units. After applying these cut-offs and deriving secondary paths (also cut-off in their non-redirected part), the outcome was a total of 3226 


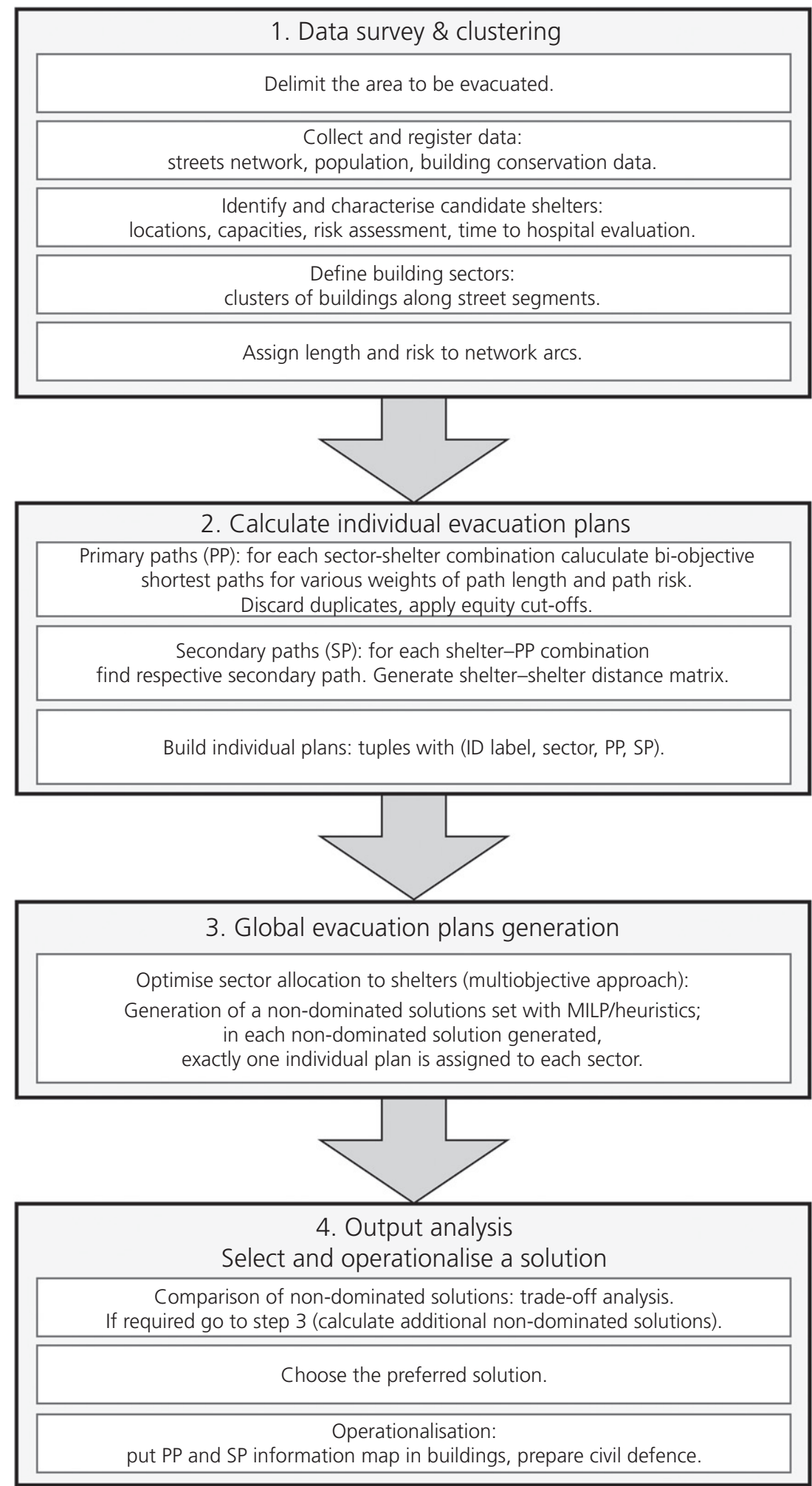

Figure 4. Procedure for implementing the evacuation strategy for densely urbanised city centres 

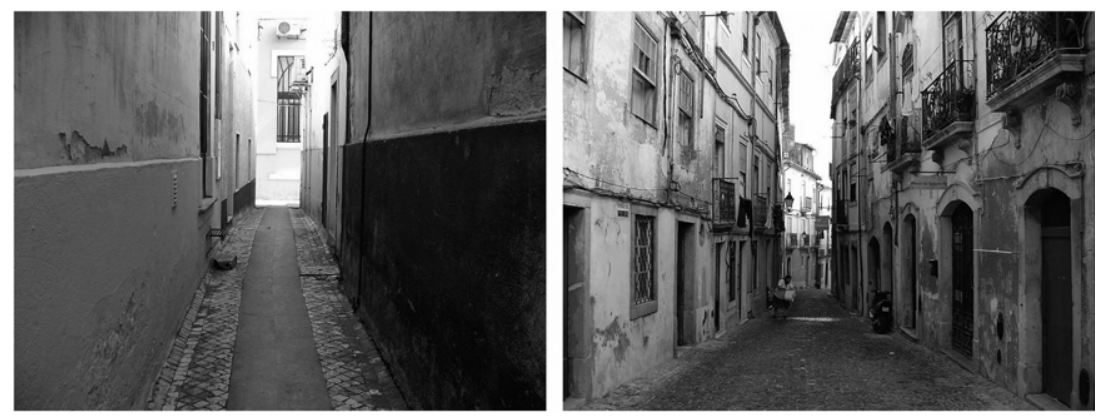

Figure 5. Urban morphology of case study area

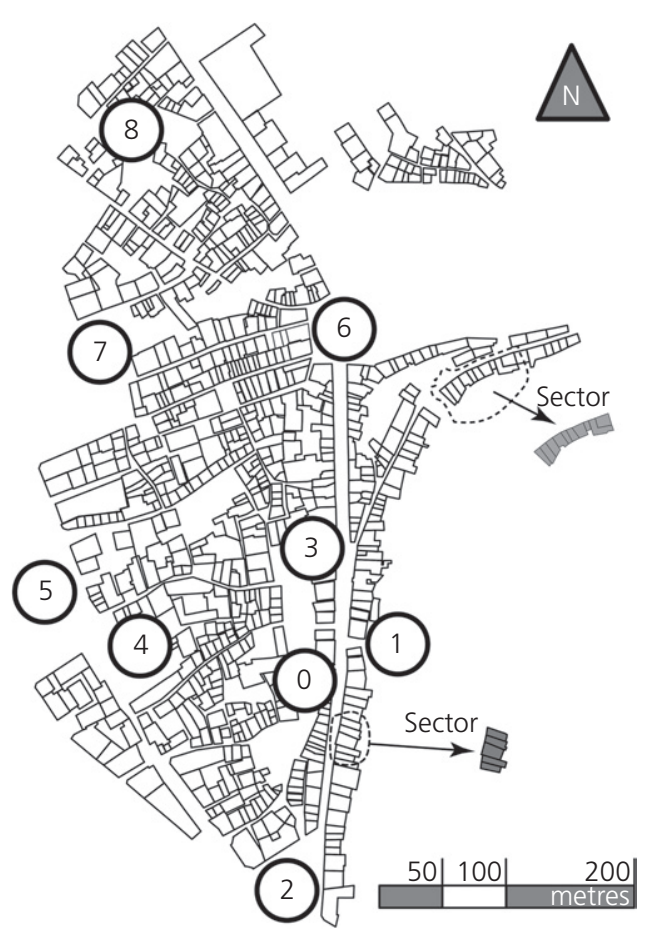

Figure 6. Buildings, clustering into sectors and candidate shelters - case study

individual plans, of which 3088 were to be used during the day and 2279 at night.

\subsection{Case study - step 3}

Both MILP and GA heuristics were used to derive results for the case study. The MILP method yielded exact results for O1-O6 and two normalised weights combinations, $W_{1}=$ $(45,10,15,10,10,10)$ and $W_{2}=(10,20,10,25,25,10)$, reflecting decision-makers' focus on path length $\left(W_{1}\right)$ and risks/transport time $\left(W_{2}\right)$ (both for the night instance). Normalisation used was that of Tralhão et al. (2010).

\begin{tabular}{lccc}
\hline Instance & $\begin{array}{c}\text { Population to } \\
\text { evacuate }\end{array}$ & $\begin{array}{c}\text { Sectors to } \\
\text { evacuate }\end{array}$ & $\begin{array}{c}\text { Total shelter } \\
\text { maximum capacity }\end{array}$ \\
\hline Day & 5663 & 192 & 14300 \\
Night & 1265 & 143 & 4600
\end{tabular}

Table 1. Geographic and demographic data of the case study

Heuristics were implemented with the divide-and-conquer approach. Data were prepared by discarding infeasible shelter combinations and invalid individual plans for each respective sub-problem. Each subset of data was plugged into an evolutionary algorithm (Distributed Evolutionary Algorithms in Python (DEAP) library used, Fortin et al., 2012), which ran on weighted sum and front searching Non-dominated Sorting Genetic Algorithm-II (NSGAII) modes (Deb et al., 2002), with standard two-point crossover and mutation operators. Initial population was seeded near the uncapacitated optimum and the number of generations was made proportional to a prefactor, $c p$ (set at runtime) times the logarithm of the combinatorial complexity of the sub-problem at hand. The $c p$ was made higher for NSGAII, as this is a more difficult problem to solve. Infeasibility was treated with penalty functions linear on the number of people outside the shelter $\mathrm{min} / \mathrm{max}$ capacity.

Heuristics redid the MILP simple model calculations, so as to have a grasp on how well they performed. After this, two runs were done in the extended model (redirecting term set to $R=0 \cdot 5$ ). Table 2 summarises these results. Scores are shown in average per evacuee and in the following units: metres $(\mathrm{O} 1, \mathrm{O} 3)$, risk units $(\mathrm{O} 2, \mathrm{O} 4)$ and seconds $(\mathrm{O} 5)$.

Clearly heuristic results, which are new, are competitive with MILP ones (even coinciding for some of the easier problems), meaning the method can be applied to realistic problem instances, simple or extended models. The NSGAII results are, as expected, less precise than weighted sum runs (harder problem), but it should be noted that one run yields a very 


\begin{tabular}{|c|c|c|c|c|c|c|}
\hline Solution & Calculation method & 01 & $\mathrm{O} 2$ & $\mathrm{O} 3$ & $\mathrm{O} 4$ & O5 \\
\hline Ideal (day) & MILP & $77 \cdot 8$ & $54 \cdot 6$ & $75 \cdot 8$ & $44 \cdot 2$ & $268 \cdot 2$ \\
\hline Ideal (day) & Heuristic WS & 84.9 & $61 \cdot 7$ & $75 \cdot 8$ & $44 \cdot 2$ & $268 \cdot 2$ \\
\hline Ideal (day) & Heuristic NSGAll & $102 \cdot 6$ & $70 \cdot 7$ & $83 \cdot 2$ & $45 \cdot 7$ & $268 \cdot 2$ \\
\hline Ideal (night) & MILP & $85 \cdot 2$ & 51 & $89 \cdot 6$ & $43 \cdot 4$ & $168 \cdot 4$ \\
\hline Ideal (night) & Heuristic WS & $88 \cdot 4$ & $52 \cdot 6$ & $89 \cdot 6$ & $43 \cdot 6$ & $168 \cdot 4$ \\
\hline Ideal (night) & Heuristic NSGAll & $106 \cdot 5$ & $63 \cdot 4$ & $95 \cdot 3$ & $44 \cdot 1$ & $168 \cdot 4$ \\
\hline$W_{1}$ (night) & MILP & $120 \cdot 6$ & $74 \cdot 5$ & $145 \cdot 1$ & $92 \cdot 6$ & $188 \cdot 4$ \\
\hline$W_{1}$ (night) & Heuristic WS & $121 \cdot 3$ & $75 \cdot 5$ & $157 \cdot 9$ & 91.9 & $191 \cdot 8$ \\
\hline$W_{1}$ (night) & Heuristic NSGAll & $141 \cdot 8$ & $86 \cdot 6$ & $152 \cdot 6$ & $102 \cdot 4$ & $183 \cdot 8$ \\
\hline$W_{2}$ (night) & MILP & $152 \cdot 3$ & $82 \cdot 3$ & $123 \cdot 1$ & $72 \cdot 7$ & $179 \cdot 4$ \\
\hline$W_{2}$ (night) & Heuristic WS & $154 \cdot 6$ & $86 \cdot 2$ & $124 \cdot 7$ & $72 \cdot 3$ & $179 \cdot 9$ \\
\hline$W_{2}$ (night) & Heuristic NSGAll & 186 & $114 \cdot 4$ & $139 \cdot 2$ & $76 \cdot 1$ & $173 \cdot 9$ \\
\hline $\mathrm{O} 3$ opt (night) $R=0.5$ & Heuristic WS & - & - & $91 \cdot 3$ & - & - \\
\hline$W_{2}$ (night) $R=0.5$ & Heuristic WS & $155 \cdot 9$ & 87 & $200 \cdot 6$ & $70 \cdot 4$ & $181 \cdot 9$ \\
\hline
\end{tabular}

Table 2. Objectives scores - case study ( $R=0$ unless otherwise stated). WS, weighted sum

large number of non-dominated solutions. Indeed, 1300-1600 globally non-dominated solutions were found (only three are shown in the table), which is too high a number to study trade-offs. The number can however be reduced to a few representatives of their respective neighbourhood by applying a filtering method, like that of, for example, Mattson et al. (2004).

Note also that the redirection term did change the O3 (night) optimum, although not by much. This was because for $R=0$ the $\mathrm{O} 3$ optimum is obtained with nearly all shelters open, so very few redirecting is necessary. For $W_{2}$ however, only three shelters are open, so a lot of redirecting is happening and therefore the secondary path length increases significantly, as the table shows.

\subsection{Case study - step 4}

A thorough study of the Pareto front and refinements from weighted sum runs clearly hinted at three to four open shelter solutions being preferred for most weights combinations. A graphical display of one of the possible solutions for implementation, heuristic $W_{2}$ (extended model), is shown in Figure 7. This result can only be obtained from the heuristic approach.

In the figure, grey intensity of filled polygons represents shelter allocation.

More solutions were analysed (not shown in Table 2), and it was interesting to note that the best solutions ignore redundant shelters by showing a tendency to select only one shelter when a few are available in the same area.

\subsection{Concluding remarks}

The case study shows how the methodology can be applied successfully and its outcome hints at what the best solutions will look like in general. Inspection of Table 2 solutions revealed that the trend of Figure 7 is systemic, in that the location-allocation model of step 3 tends to open the largest/ safest shelters and direct people in the vicinity there. The case study also provides some figures on the combinatorial size of the problem and show that the associated computational complexity is treatable. Solvability of large problem instances (e.g. large city centres) is guaranteed by the heuristic approach, even if approximately. On the practical side, testing a solution can be done by way of an evacuation simulation. Such a simulation can help identify issues on the field that may arise in a real call-out, thus providing decision-makers with valuable feedback.

\section{Summary and outlook}

The urban engineering task of designing evacuation plans is a hard one, with many aspects that need to be attended and of high mathematical complexity. In this paper, a self-contained methodology was presented that can guide decision-makers through the process of designing such plans for contexts of densely urbanised city centres, where motorised evacuation is impossible or not preferred. The various steps of the process were described, along with the most important details for practical implementation. The methodology consists of four stages, from preliminary studies to modelling and implementation, and aims at optimising six objectives that are important in disaster situations. The case study new heuristic results have shown that the methodology is applicable to any real-sized 


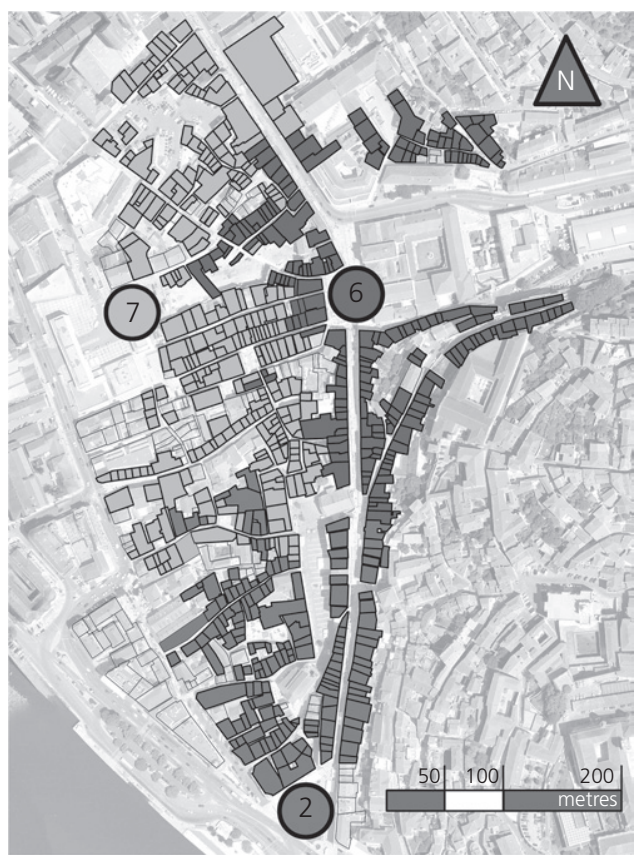

Figure 7. Building shelter allocation - heuristic $W_{2}$ (night) with redirection

problem. The fact that it treats many aspects of evacuation simultaneously adds to its relevance.

As future research it would be interesting to test the approach in more case studies and check its sensitivity to specific data. In the methodological front, a possible direction is to develop and optimise heuristics to deal with situations where a large number of shelters needs to be considered.

\section{Acknowledgements}

This work was partially supported by the Portuguese Foundation for Science and Technology under grant PEst-OE/ EEI/UI308/2014; and the initiative Energy for Sustainability of the University of Coimbra, supported by project Energy and Mobility for Sustainable Regions (EMSURE), under grant CENTRO-07-0224-FEDER-002004.

\section{Appendix 1: Shelter allocation optimisation model}

Adapted from Coutinho-Rodrigues et al. (2012).

Let the tuple $p_{k}=\left(k, s_{k}, p_{k}^{1}, p_{k}^{2}\right)$ be an individual evacuation plan, with

\footnotetext{
$k$ : identifier field, $k=1, \ldots, K$, with $K$ being the total number of individual plans

$s_{k}$ : sector evacuated by plan $p_{k}$
}

$p_{k}^{1}$ : primary path of plan $p_{k}$

$p_{k}^{2}$ : secondary path of plan $p_{k}$

Model

$$
\begin{aligned}
\min \mathrm{O} 1 & =\sum_{i=1}^{K} \ell_{i}^{1} h_{s_{i}} x_{i} \\
\min \mathrm{O} 2 & =\sum_{i=1}^{K} r_{i}^{1} h_{s_{i}} x_{i} \\
\min \mathrm{O} 3 & =\sum_{i=1}^{K} \ell_{i}^{2} h_{s_{i}} x_{i}+R \sum_{i: x_{i}=1} \ell_{i}^{3} h_{s_{i}} x_{i} \\
\min \mathrm{O} 4 & =\sum_{i=1}^{K} r_{e_{i}^{1}}^{e} h_{s_{i}} x_{i} \\
\min \mathrm{O} 5 & =\sum_{i=1}^{K} t_{e_{i}^{1}} h_{s_{i}} x_{i} \\
\min \mathrm{O} 6 & =\sum_{j=1}^{N_{e}} y_{j}
\end{aligned}
$$

subject to

$$
\begin{aligned}
& \sum_{i: s_{i}=k} x_{i}=1 ; \quad k=1, \ldots, N_{\mathrm{s}} \\
& c_{j}^{\mathrm{m}} y_{j} \leq \sum_{i: e_{i}^{1}=j} h_{s_{i}} x_{i} \leq c_{j}^{\mathrm{M}} y_{j} ; \quad j=1, \ldots, N_{e} \\
& \ell_{i}^{3}=\min \left\{\ell_{e_{i}^{2}, j}^{e} ; \quad i, j: x_{i}=y_{j}=1\right\}
\end{aligned}
$$

where

$x_{i}=1$ if individual plan $i$ is chosen, 0 otherwise (decision variable)

$y_{j}=1$ if candidate shelter $j$ is opened, 0 otherwise (decision variable)

$N_{\mathrm{s}}$ : number of sectors to evacuate

$N_{e}$ : number of candidate shelters

$h_{s i}$ : population of sector $s_{i}$

$\ell_{i}^{1}$ : length of primary path $p_{i}^{1}$

$\ell_{i}^{2}$ : length of secondary path $p_{i}^{2}$

$r_{i}^{1}$ : risk associated with primary path $p_{i}^{1}$

$e_{i}^{1}$ : primary shelter of individual plan $i$ (destination of path $p_{i}^{1}$ )

$e_{i}^{2}$ : secondary shelter of individual plan $i$ (destination of path $p_{i}^{2}$ )

$r_{e_{1}^{1}}^{e}$ : risk associated with primary shelter of individual plan $i$

$t_{e_{i}^{1}}$ : time cost required to move people out of primary shelter of individual plan $i$

$c_{j}^{\mathrm{m}}$ : minimum number of individuals required to open shelter $j$ $c_{j}^{\mathrm{M}}$ : maximum number of individuals allowed in shelter $j$

$\ell_{e_{i}^{2}, j}^{e}:$ shortest exterior path from shelter $e_{i}^{2}$ to shelter $j$

$R$ is the parameter s.t. $0 \leq R \leq 1$. If $R=0$ the model is simple; if $R>0$ the model is complete or extended. 


\section{REFERENCES}

Ahrens M (2015) Home Structure Fires. National Fire

Protection Association, MA, USA. See www.nfpa.org/ $\%$

7E/media/Files/Research/NFPA\%20reports/Occupancies/ oshomes.pdf (accessed 18/05/2015).

Alçada-Almeida L, Tralhão L, Santos L and Coutinho-Rodrigues J (2009) A multiobjective approach to locate emergency shelters and identify evacuation routes in urban areas. Geographical Analysis 41(1): 9-29.

AQ (Association Qualitel) (2011) CERQUAL Patrimoine. Le Bilan Patrimoine Habitat. Contenu, Exigences, Processus et Outils. Référentiel Millésime 2011. Association Qualitel, Paris, France (in French).

ASCE (American Society of Civil Engineers) (2007a) The New Orleans Hurricane Protection System: What Went Wrong and Why. American Society of Civil Engineers, A Report by the American Society of Civil Engineers Hurricane Katrina External Review Panel, Reston, VA, USA. http:// ascelibrary.org/doi/pdf/10.1061/9780784408933 (accessed 06/09/2015).

ASCE (2007b) The Vision for Civil Engineering in 2025. American Society of Civil Engineers, Reston, VA, USA. https://www. asce.org/uploadedFiles/About_Civil_Engineering/Content_ Pieces/vision2025.pdf (accessed 06/09/2015).

Belton V and Stewart T (2010) Problem structuring and MCDA. In Trends in Multiple Criteria Decision Analysis (Ehrgott M, Figueira J and Greco S (eds)). Springer, New York, NY, USA, Chapter 8, pp. 209-239.

Booth R (2012) Risk planning for interdependencies: from theory to practice. Proceedings of the Institution of Civil Engineers - Municipal Engineer 165(2): 85-92, http://dx.doi.org/10.1680/muen.11.00032.

Brachman M and Dragicevic S (2014) A spatially explicit network science model for emergency evacuations in an urban context. Computers, Environment and Urban Systems 44: 15-26.

Chang $\mathrm{H}$, Lai $\mathrm{C}$ and Hwang $\mathrm{H}$ (2012) Spatial performance to locate city fire stations. Proceedings of the Institution of Civil Engineers - Municipal Engineer 165(1): 19-29, http://dx.doi.org/10.1680/muen.2012.165.1.19.

Chu J and Su Y (2012) The application of TOPSIS method in selecting fixed seismic shelter for evacuation in cities. Systems Engineering Procedia - Information Engineering and Complexity Science - Part I 3: 391-397.

Civil Contingencies Act 2004 (2004) Chapter 36, received Royal Assent on 18 November 2004. See http://www.legislation. gov.uk/ukpga/2004/36/pdfs/ukpga_20040036_en.pdf.

Cohon J (1978) Multiobjective Programming and Planning. Academic Press, New York, NY, USA.

Coutinho-Rodrigues J, Clímaco J and Current J (1999) An interactive bi-objective shortest path approach: searching for non-supported nondominated solutions. Computers and Operations Research 26(8): 789-798.
Coutinho-Rodrigues J, Tralhão L and Alçada-Almeida L (2012) Solving a location-routing problem with a multiobjective approach: the design of urban evacuation plans. Journal of Transport Geography 22: 206-218.

Daskin M (1982) Application of an expected covering model to EMS system design. Decision Sciences 13(3): 416-439.

Daskin M and Stern E (1981) A hierarchical objective set covering model for EMS vehicle deployment. Transportation Science 15(2): 137-152.

DCLG (Department for Communities and Local Government) (2006) Home Information Pack: Standards for Certification Schemes. Part 2: Technical Standards. DCLG, London, UK. http://collections.europarchive.org/tna/20060704081714/ http://communities.gov.uk/embedded_object.asp?id= 1500776 (accessed 07/09/2015).

Deb K, Pratap A, Agarwal S and Meyarivan T (2002) A fast and elitist multiobjective genetic algorithm: NSGA-II. IEEE Transactions on Evolutionary Computation 6(2): 182-197.

Dobbernack R and Klingenberg M (2005) Fire Risk Assessment Methods, WG 6 in Fire Risk Evaluation to European Cultural Heritage, Fifth Framework Programme, Gent, Belgium.

D'Orazio M, Quagliarini E, Bernardini G and Spalazzi L (2014) EPES - earthquake pedestrians' evacuation simulator: a tool for predicting earthquake pedestrians' evacuation in urban outdoor scenarios. International Journal of Disaster Risk Reduction 10: 153-177.

Erkut E and Ingolfsson A (2000) Catastrophe avoidance models for hazardous materials route planning. Transportation Science 34(2): 165-179.

Fortin F, Rainville F, Gardner M, Parizeau M and Gagné C (2012) DEAP: evolutionary algorithms made easy. Journal of Machine Learning Research 13: 2171-2175.

Gershon R, Magda L, Riley H and Sherman M (2012) The world trade center evacuation study: factors associated with initiation and length of time for evacuation. Fire and Materials: Special Issue on Human Behaviour in Fire 36(5-6): 481-500.

Goerigk M, Grun B and Hessler P (2013) Branch and bound algorithms for the bus evacuation problem. Computers and Operations Research 40(12): 3010-3020.

Kailiponi P (2010) Analyzing evacuation decisions using multi-attribute utility theory (MAUT). Procedia Engineering - First Conference on Evacuation Modeling and Management 3: 163-174.

Kara B and Verter V (2004) Designing a road network for hazardous materials transportation. Transportation Science 38(2): 188-196.

Kicinger R and Bronzini M (2006) Model of a self-organizing traffic management hazard response system. In Applications of Advanced Technology in Transportation (Kelvin CP, Wang K, Smith B, Uzarski B and Wong S (eds)). Transportation \& Development Institute (T\&DI), 
American Society of Civil Engineers, Reston, VA, USA, pp. 374-380. http://dx.doi.org/10.1061/40799(213)59.

Kongsomsaksakul S, Yang C and Chen A (2005) Shelter location-allocation model for flood evacuation planning. Journal of the Eastern Asia Society for Transportation Studies 6: 4237-4252.

Kunwar B, Simini F and Johansson A (2014) Large scale pedestrian evacuation modeling framework using volunteered geographical information. Transportation Research Procedia 2: 813-818.

Larsson D (2000) Developing the Structure of a Fire Index Method for Timber-frame Multi-storey Apartment Buildings. Department of Fire Safety Engineering, Lund University, Lund, Sweden, Report 5062. http://lup. lub.lu.se/luur/download?func $=$ downloadFile\&recordOId $=$ 1687186\&fileOId=1691831 (accessed 07/09/2015).

Li A, Nozick L, Xu N and Davidson R (2012) Shelter location and transportation planning under hurricane conditions. Transportation Research Part E: Logistics and Transportation Review 48(4): 715-729.

Lim G, Zangeneh S, Baharnemati M and Assavapokee T (2012) A capacitated network flow optimization approach for short notice evacuation planning. European Journal Operation Research 223(1): 234-245.

Liu H, He X and Ban J (2007) A cell-based many-to-one dynamic system optimal model and its heuristic solution method for emergency evacuation. Transportation Research Board 86th Annual Meeting Compendium of Papers, Report 07-2261. Transportation Research Board Business Office, Washington DC, USA. http://trid.trb.org/view.aspx? id=802113 (accessed 28/08/2015).

Marquet $O$ and Miralles-Guasch C (2014) Walking short distances. The socioeconomic drivers for the use of proximity in everyday mobility in Barcelona. Transportation Research Part A: Policy and Practice 70: 210-222.

Mattson C, Mullur A and Messac A (2004) Smart Pareto filter: obtaining a minimal representation of multiobjective design space. Engineering Optimization 36(6): 721-740.

McAlinden B (2014) Flood Prevention in Manhattan. Institution of Civil Engineers. See https://www.ice.org.uk/ disciplines-and-resources/case-studies/flood-prevention-inmanhattan (accessed 18/05/2015).

McRobert J (2010) Flooding and the role of the local authority. Proceedings of the Institution of Civil Engineers Municipal Engineer 163(4): 257-262, http://dx.doi.org/ 10.1680/muen.2010.163.4.257.

Miller G (2014) New York: Adapting to the Threat of Flooding. Institution of Civil Engineers. See https://www.ice.org.uk/ disciplines-and-resources/case-studies/new-york-adaptingto-the-threat-of-flooding (accessed 18/05/2015).

Mishima N, Miyamoto N, Taguchi Y and Kitagawa K (2014) Analysis of current two-way evacuation routes based on residents' perceptions in a historic preservation area. International Journal of Disaster Risk Reduction 8: 10-19.

Murray-Tuite P and Wolshon B (2013) Evacuation transportation modelling: an overview of research, development, and practice. Transportation Research Part C: Emerging Technologies 27: 25-45.

Natividade-Jesus E, Coutinho-Rodrigues J and Tralhão L (2013) Housing evaluation with web-SDSS in urban regeneration actions. Proceedings of the Institution of Civil Engineers - Municipal Engineer 166(3): 194-207, http://dx. doi.org/10.1680/muen.12.00022.

NEN (Nederlands Normalisatie-Instituut) (2006) NEN 2767-1:2006 - Conditiemeting van Bouwen Installatiedelen - Deel 1: Methodiek. NEN, Delft, the Netherlands (in Dutch).

NFPA (National Fire Protection Association) (1995) The Society of Fire Protection Engineering Handbook of Fire Engineering, 2nd edn. National Fire Protection Association, Quincy, MA, USA. ISBN: 0-87765-354-2.

NFPA (2001) NFPA 914: Code for Fire Protection of Historic Structures. National Fire Protection Association, Quincy, MA, USA.

Plyer A (2015) Facts for Features: Katrina Impact. The Data Centre. See http://www.datacenterresearch.org/dataresources/katrina/facts-for-impact/ (accessed 18/05/2015).

ReVelle C (1989) Review, extension and prediction in emergency service siting models. European Journal of Operational Research 40(1): 58-69.

ReVelle C and Eiselt H (2005) Location analysis: a synthesis and survey. European Journal of Operational Research 165(1): $1-19$.

ReVelle C and Snyder S (1995) Integrated fire and ambulance sitting: a deterministic model. Socio-Economic Planning Sciences 29(4): 261-271.

Rogers CDF, Bouch CJ, Williams S et al. (2012) Resistance and resilience - paradigms for critical local infrastructure. Proceedings of the Institution of Civil Engineers Municipal Engineer 165(2): 73-83, http://dx.doi.org/ 10.1680/muen.11.00030.

Saadatseresht M, Mansourian A and Taleai M (2009) Evacuation planning using multiobjective evolutionary optimization approach. European Journal of Operational Research 198(1): $305-314$.

Sayyady F and Eksioglu SD (2010) Optimizing the use of public transit system during no-notice evacuation of urban areas. Computers and Industrial Engineering 59(4): 488-495.

Schilling D, Elzinga D, Cohon J, Church R and ReVelle C (1979) The team/fleet models for simultaneous facility and equipment siting. Transportation Science 13(2): 163-175.

Schilling D, ReVelle C, Cohon J and Elzinga D (1980) Some models for fire protection locational decisions. European Journal of Operational Research 5(1): 1-7. 
Sherali H, Carter T and Hobeika A (1991) A location-allocation model and algorithm for evacuation planning under hurricane/flood conditions. Transportation Research Part B: Methodological 25(6): 439-452.

Stainsby A (2012) Briefing: emergency planning and the UK Civil Contingencies Act 2004. Proceedings of the Institution of Civil Engineers - Municipal Engineer 165(2): 69-71, http://dx.doi.org/10.1680/muen.12.00012.

Stella K and Daganzo C (2010) Managing evacuation routes. Transportation Research Part B 44(4): 514-520.

Toregas C, Swain R, ReVelle C and Bergman L (1971) The location of emergency services. Operations Research 19(6): 1363-1373.
Tralhão L, Coutinho-Rodrigues J and Alçada-Almeida L (2010) Multiobjective modeling approach to locate multi-compartment containers for urban sorted waste. Waste Management 30(12): 2418-2429.

Verma M, Verter V and Gendreau M (2011) A tactical planning model for railroad transportation of dangerous goods. Transportation Science 45(2): 163-174.

Yildirim V, Yomralioglu T, Nisanci R and Inan H (2014) Turkish street addressing system and geocoding challenges. Proceedings of the Institution of Civil Engineers Municipal Engineer 167(2): 99-107, http://dx.doi.org/ 10.1680/muen.13.00008.

\section{HOW CAN YOU CONTRIBUTE?}

To discuss this paper, please email up to 500 words to the editor at journals@ice.org.uk. Your contribution will be forwarded to the author(s) for a reply and, if considered appropriate by the editorial board, it will be published as discussion in a future issue of the journal.

Proceedings journals rely entirely on contributions from the civil engineering profession (and allied disciplines). Information about how to submit your paper online is available at www.icevirtuallibrary.com/page/authors, where you will also find detailed author guidelines. 